\title{
EFFECTS OF SELECTED TOTAL QUALITY PRACTICES AND INNOVATION PERCEPTION ABOUT MARKET COMPETITION OF MANAGERS ON PRODUCT QUALITY AND INNOVATION
}

\author{
DOI: 10.17261/Pressacademia.2018.900 \\ PAP- V.7-2018(53)-p.290-294
}

Mehmet Colak ${ }^{1}$, Cengiz Duran ${ }^{2}$, Sema Behdioglu ${ }^{3}$, Hayrettin Ozler ${ }^{4}$, Tahsin Cetin ${ }^{5}$

${ }^{1}$ Mugla Sitki Kocman University, Technology Faculty, Woodworking Industrial Engineering, 48000, Kötekli Campus, Mugla, Turkey. cmehmet@mu.edu.tr, ORCID: 0000-0003-4780-587X

${ }^{2}$ Dumlupınar University, Faculty of Economics and Administrative Sciences, 43000, Central Campus, Kutahya, Turkey. cengizduran@dpu.edu.tr, ORCID: 0000-0001-7910-0677

${ }^{3}$ Dumlupınar University, Faculty of Economics and Administrative Sciences, 43000, Central Campus, Kutahya, Turkey. sema.behdioglu@dpu.edu.tr, ORCID: 0000-0002-4759-2088

${ }^{4}$ Dumlupınar University, Faculty of Economics and Administrative Sciences, 43000, Central Campus, Kutahya, Turkey. hayrettin.ozler@dpu.edu.tr, ORCID: 0000-0001-7056-4061

${ }^{5}$ Mugla Sitki Kocman University, Technology Faculty, Woodworking Industrial Engineering, 48000, Kötekli Campus, Mugla, Turkey. tahsincetin@mu.edu.tr, ORCID: 0000-0002-7886-981X

To cite this document

Colak, M., Duran, C., Behdioglu, S., Ozler, H., Cetin, T. (2018). Effects of selected total quality practices and innovation perception about market competition of managers on product quality and innovation. PressAcademia Procedia (PAP), V.7, p.290-294.

Permemant link to this document: http://doi.org/10.17261/Pressacademia.2018.900

Copyright: Published by PressAcademia and limited licenced re-use rights only.

\section{ABSTRACT}

Purpose- Innovation is vital both for developing and developed countries in today's world. It is also crucial for a developed economy and an increased welfare. It is to establish the useful method in detecting the incompetencies in innovation of middle-sized furniture businesses operating in Turkey, develop suggestions for solution and to improve their innovation proficiencies within market competition.

Methodology- To determine the shortest ways of implementing these innovative leaps for businesses and to make a scientific contribution to the developed and developing furniture industry in Turkey.

Findings- the convenient model for businesses to make practical innovative changes and gain awareness and to succeed and survive in a more challenging, competitive market environment is stated.

Conclusion- Possible alternative models were developed directed towards the established model and shared with the involved businesses. As a result of the model established with mediator variables, the effect of innovation perception on technology management / R\&D and product quality / innovation is found to be exact and more significant than other variables.

Keywords: Market competition, product innovation, TQM practices, innovation.

JEL Codes: D22, E30, L20

\section{PAZAR REKABETI KAPSAMINDA YÖNETICILERIN INOVASYON ALGISI ILE SEÇILEN TOPLAM KALITE} UYGULAMALARININ ÜRÜN KALITESINE VE INOVASYONUNA ETKISI

\section{ÖZET}

Amaç- İnovasyon, günümüzde hem gelişmekte olan hem de gelişmiş ülkeler açısından çok önemlidir. Ülke ekonomisinin gelişmesinde ve refah düzeyinin artmasında da kilit bir etkendir. Türkiye de faaliyette bulunan orta büyüklükteki mobilya işletmelerinin inovasyon yapmadaki yetersizliklerini ortaya çıkarıp bu yetersizliklere çözüm önerileri geliştirip pazar rekabeti kapsamında inovasyon yeterliliği kazandıracak faydalı modelin oluşturulmasıdır.

Yöntem- Bu model kapsamında söz konusu işletmelerin hangi yöntemi uygularlarsa daha kısa yoldan inovatif hamleleri gerçekleştirebileceğinin görmesini sağlamak ve gelişen gelişmekte olan Türkiye mobilya sektör ekonomisine bilimsel nitelikte katkılar sağlamaktır.

Bulgular- İşletmelerin daha pratik inovatif hamle yapmasına ve farkındalık kazanmasına yardımcı olarak zorlaşan pazar rekabeti koşullarında başarılı olarak ayakta kalmalarını sağlayacak uygun model belirlenmiştir.

Sonuç- Kurulan modele yönelik alternatif olası modellerde geliştirilip ilgili işletmelerle paylaşılmıştır. Aracı değişkenler ile kurulan model göre; Pazar rekabeti kapsamında inovasyon algısının teknoloji yönetimi/ar-ge aracı değişkeni ile ürün kalitesi ve inovasyonuna etkisi modeldeki diğer değişkenlere göre daha anlamlı olduğu ve tam aracılık etkisi gösterdiği saptanmıştır.

Anahtar Kelimeler: Pazar rekabeti, ürün inovasyonu, TKY uygulamaları, inovasyon.

JEL Kodları: D22, E30, L20 


\section{GíRiş}

Yeniliğe eğimli davranışların ortaya çıkarılarak mobilya işletmelerinin ürün tasarımında ve yeni teknolojilere uyum sağlamasında işletme örgüt kültürünün sahip olduğu toplam kalite uygulamaları müşteri isteklerini karşılama bakımından değerlidir.

İşletmeler kurum içinde inovasyon kültürünü oluşturup tüm çalışanlarına benimsetmek durumundadırlar. Yöneticiler ile alt kademe çalışanlar arasındaki bu algı farkı bize insanların inovatif fikirlere değer verdiğini söylemesi fakat onların uygulamada bunu göstermemeleri çalışanlar tarafından olumsuz davranış sergilemelerine yol açmaktadır. Örneğin üst kademe yöneticilerin alt kademe yöneticilere yeniliklere, inovatif girişimlere değer verdiğini söyleyip fakat daha geleneksel ve uysal astları tercih etmeleri bunu kanıtlar niteliktedir.

Işletmelerde inovasyon fikri ya yöneticilerden ya da çalışanlardan geliyor olabilir fakat fikir ve uygulamanın iş organizasyonlarında inovasyonun yararları konusunda çalışanların bunu kabullenmesi, ikna edilmesi, karar ve uygulama sürecine katılımı ve süreç içinde çalışanların görüşlerinin dikkate alındığı algısı uygulama sürecinin en önemli kısmını oluşturmaktadır.

\section{LITERATÜR INCELEMESI}

Schumpeter'ın 1934 yılında ortaya atmasıyla başlayan inovasyon kavramı özellikle rekabet avantajı sağlamada farklılaştırma stratejisinin ön plana çıktığı sanayi işletmelerinde önemini devamlı korumuştur. Son yıllarda işletme ve ekonomik alanlarda inovasyon konusunun yoğun olarak incelendiği araştırıldığı görülmektedir. Ayrıca Türkiye'de de 2012 yılından itibaren başlayarak devam eden İnovasyon Haftası adı altında devlet tarafından bir etkinlik tertip edilmesi bu kavramın ve uygulamaların önemini belirgin hale getirmektedir.

Günümüz işletmelerinin çevreye duyarlı canlı yaşayan bir örgüt yapısı olduğu gerçeğinden yola çıkıldığında gelişen değişen dünyaya uyum sağlamak en önemli hedefler arasındadır (Choo, 2002).

İşletmeler günümüzde bilgiyi üretip aynı zamanda kullanan ve bunu inovasyon çercevesinde değerlendirebilen ileri görüşlü yöneticilere sahip olmak istemektedirler. Yöneticiler yeni fikir ve düşüncelerini işletmelerde uygulamaya dönüştürerek küresel rekabet dünyasında başarılı olabilmeleri için ürün ve hizmetlerinde yenilik yapmalı veya yeni teknolojik uygulamaları zorunluluk haline getirebilmelidir.

Çalıştığı konularda uzman yöneticilerin istihdam edilmesi yapılan işlerin kalitesi ve hızı gibi unsurlarda iyileşme sağlayarak doğrudan ve dolaylı olarak işletmelerin pazar rekabeti gücü üzerinde etki gösterecektir (Doğan ve Diğ., 2003:120). Peter Drucker'a göre, bir yöneticinin düşebileceği en büyük tuzaklardan biri inovasyonla (innovation) yeniliğin (novelty) birbiriyle karıştırılmasıdır. "İnovasyon", der Drucker, "yenilikten farklı olarak, değer yaratır." (Elçi, 2007:2). Drucker inovasyonu performans düzeyinde yeni bir değişimin ortaya çıkartılması olarak belirtirken Booz ve Hamilton dünya açısından yeni bir ürünün meydana getirilmesi, mevcut ürün karmasına yeni bir üründe iyileştirme veya revizyon yaparak ekleme yapılması, mevcut ürün maliyetlerinin düşürülmesi ya da yeniden konumlandırılması olarak ifade etmektedir (Kayabaşı vd., 2009: 453). Porter'a göre işletmelerin rekabet avantajı elde etmesi değer zincirindeki faaliyetleri yeni yöntemlerle yöneterek üstün müşteri değeri sunmasına bağlıdır. Bu durum ise inovasyonun bir etkisidir (Weerawardena, 2003: 20). Bu açıdan inovasyon yapmak ve inovasyonları kısa sürede benimsemek yoğun rekabetin olduğu sektörlerdeki işletmeler için en önemli rekabet avantajları arasında yer almaktadır (Uzkurt ve Şen, 2012: 32). Dolayısılla bir işletmenin mevcut ekonomik ortamda rekabet gücü elde etmesi ve rekabetçi konumunu koruyabilmesi için sürekli olarak inovasyon yapması gerekmektedir (Deniz, 2011: 146).

\section{VERI VE YÖNTEM}

Araştırmanın kapsamı olarak mobilya sektöründe faaliyette bulunan orta büyüklükteki işletmelerin idari yönetim kademesinde görev yapan personeli kapsamaktadır. Bu amaçla Türkiye genelinde 2017 yılında aktif faaliyet gösteren seri üretim yapan marka olmaya çalışan orta büyüklükteki işletmeler bu çalışmanın sınırılığını oluşturmaktadır. Bu kapsamda ihracat yapma değerlerine göre seçilmiş iller ise İzmir, İstanbul, Manisa, Bursa (İnegöl), Kayseri, Ankara, Çanakkale, Denizli, Burdur, Isparta, Antalya, Afyon, Uşak, Kütahya, Konya, Samsun, Sakarya, Düzce, Aydın, Ankara, Muğla olarak belirlenmiştir.

Birincil veri toplanmasında kullanılan yöntemler içerisinde en çok tercih edilen ve maliyeti az olan anket yöntemi seçilmiş ve 5'li Likert ölçeği kullanılarak uygulanmıştır. Anket soru ölçeği daha önceki çalışmalardan esinlenerek yeniden ölçek geliştirilerek sorular özgün olarak hazırlanmıştır. Elde edilen bilgi ve veriler SPSS 22 istatistik paket programı ve AMOS Yapısal Eşitlik Modeli programı ile test edilerek değerlendirilmiştir.

Pazar rekabeti kapsamında; İnovasyon algısının ürün kalitesi inovasyonu üzerindeki etkisine kıyaslama, müşteri odaklılık, stratejik plan ve teknoloji yönetimi AR-GE değişkenlerinin aracılık yapıp yapmadığı yapısal eşitlik modellemesi ile incelenmiştir (IBM SPSS Amos 21).

\section{BULGULAR}

Modele Dâhil Edilen Aracı Değişken (Mediating) Sonuçları olarak; Yapısal eşitlik modellemesinde aracılık (mediation) kavramı, değişkenler arasındaki ardışık nedensel ilişkilerin tanımlanmasında kullanılır. Pratikte aracı bir değişken (mediator), bağımsız değişken ile bağımlı değişken arasındaki tek yönlü nedensel ilişkinin (direk etki, direct effect) daha ayrıntılı biçimde ortaya konmasını sağlar. 
Şekil 1: Kıyaslama Aracı Değişkeni ile Kurulan Model

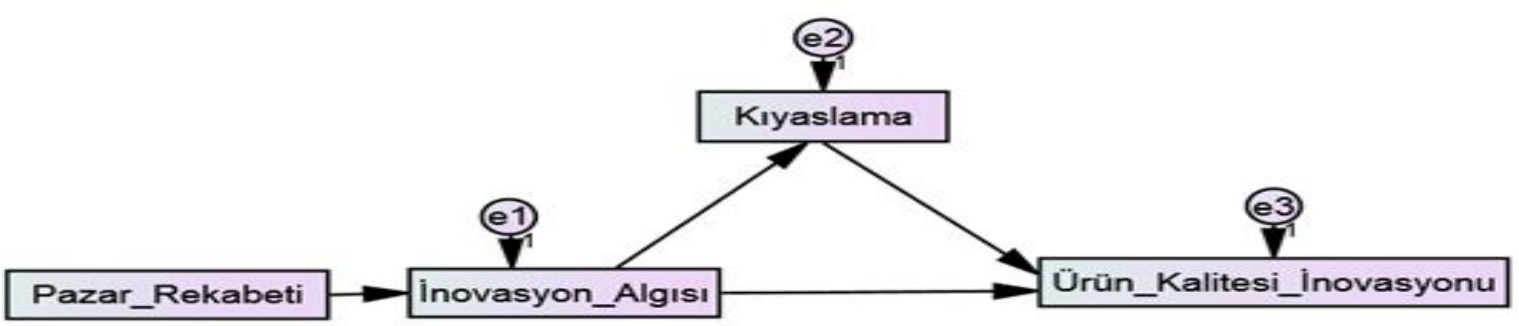

Şekil 2: Müşteri Odaklılık Aracı Değişkeni ile Kurulan Model

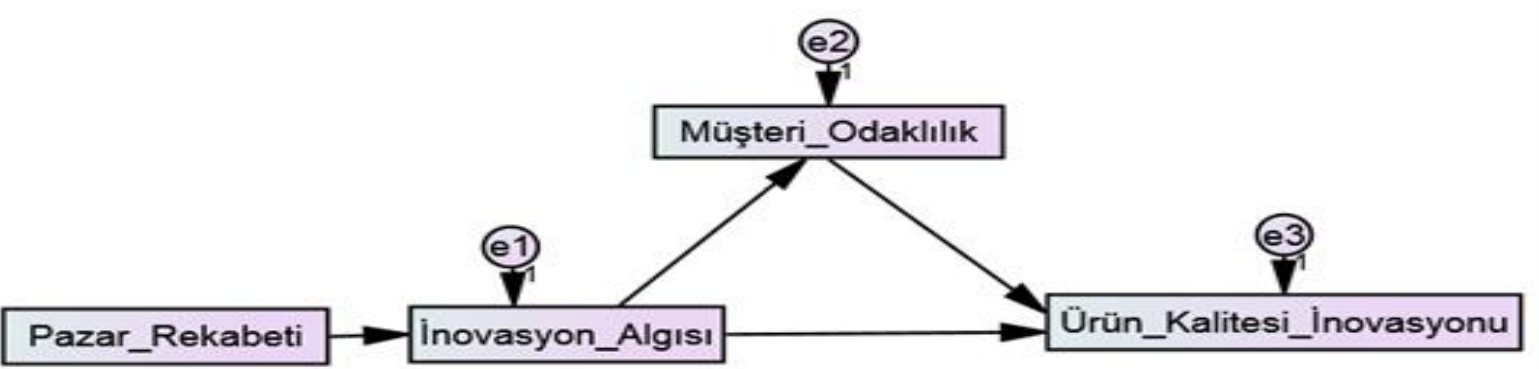

Şekil 3: Stratejik Plan Aracı Değişkeni ile Kurulan Model

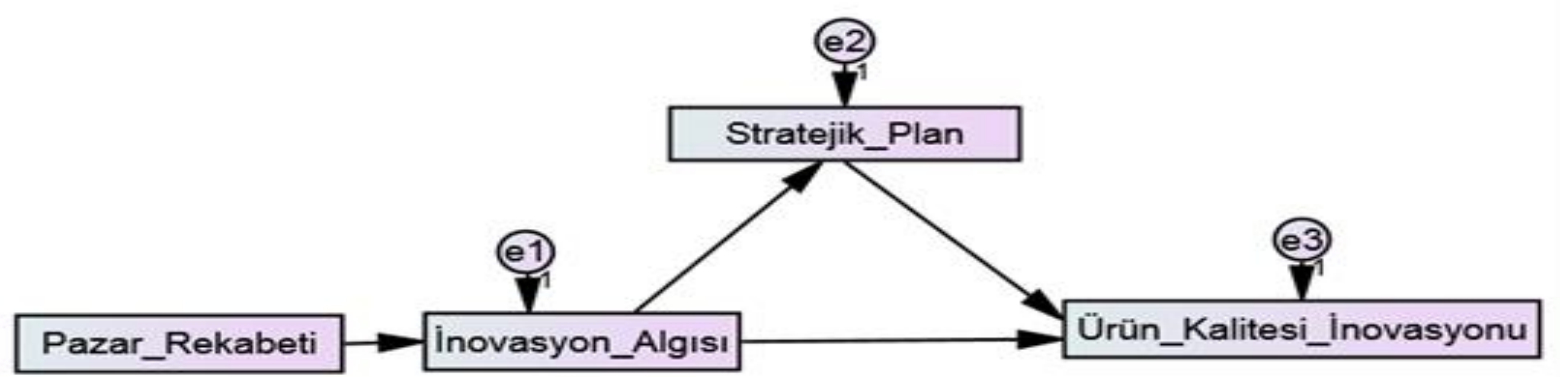

Şekil 4: Teknoloji Yönetimi AR-GE Aracı Değişkeni ile Kurulan Model

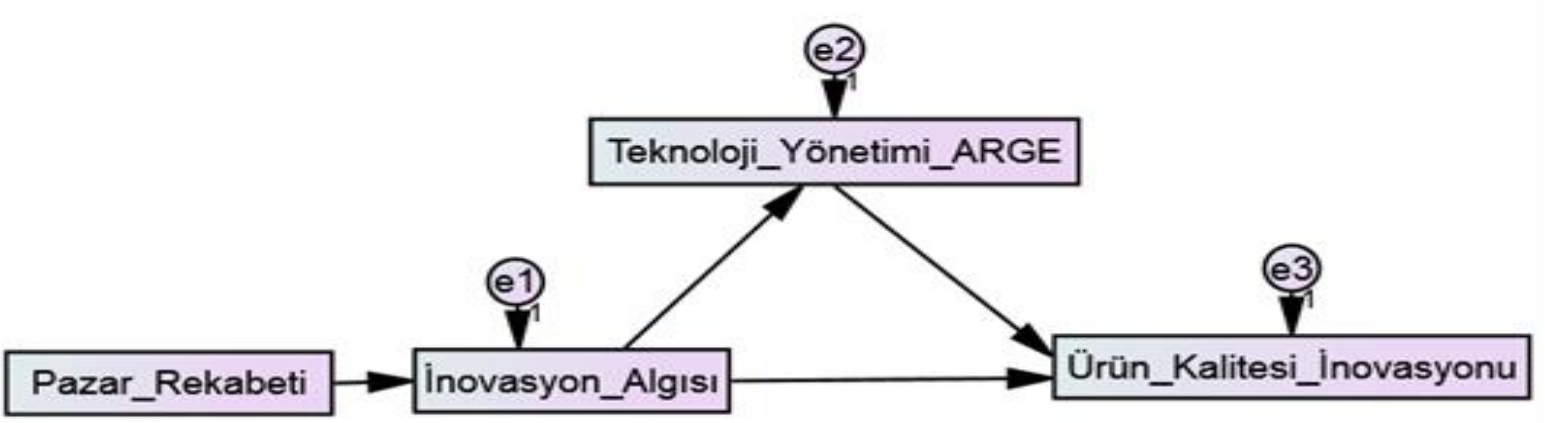

Şekillerde görüldüğü gibi "inovasyon algısı” tahmin edici (bağımsız değişken), "ürün kalitesi ve inovasyonu” tahmin edilen (bağımlı değişken) ve "kıyaslama, müşteri odaklılık, stratejik plan ve teknoloji yönetimi AR-GE" aracı (mediator) değişkenler olmak üzere; inovasyon algısından ürün kalitesi ve inovasyonuna giden direk etki istatistiksel olarak anlamlı olmalıdır. Buradaki mantık şudur; i̇ ile ÜKi arasında bir ilişki yoksa zaten aracılık edilecek bir ilişki de yok demektir. 
Aracılığın 3 çeşidi bulunmaktadır. Bunlar; dolaylı etki, kısmi aracılık ve tam aracılıktır. Kurduğumuz teorik modellerdeki kıyaslama, müşteri odaklılık, stratejik plan ve teknoloji yönetimi AR-GE değişkenlerinin aracılık edip etmediği incelenmiş olup sonuçlar aşağıdaki tabloda sunulmuştur.

Tablo 1: Aracı Değişkenler ile Kurulan Model Sonuçları

\begin{tabular}{|c|c|c|c|}
\hline Aracılığa iliş̧kin Hipotezler & $\begin{array}{l}\text { Aracı Değişken } \\
\text { Yokken }\end{array}$ & $\begin{array}{l}\text { Aracı Değişken } \\
\text { Varken }\end{array}$ & $\begin{array}{l}\text { Aracılığın } \\
\text { Çeşidi }\end{array}$ \\
\hline İnovasyon Algısı -> Kıyaslama -> Ürün Kalitesi ve İnovasyonu & \multirow{4}{*}{$0,415(p: 0,000)^{* * *}$} & $0,167(p: 0,000)^{* * *}$ & Kısmi Aracılık \\
\hline İnovasyon Algısı -> Müşteri Odaklılık -> Ürün Kalitesi ve İnovasyonu & & $0,151(p: 0,000)^{* * *}$ & Kısmi Aracilık \\
\hline İnovasyon Algısı -> Stratejik Plan -> Ürün Kalitesi ve İnovasyonu & & $0,172(p: 0,000)^{* * *}$ & Kısmi Aracılık \\
\hline $\begin{array}{l}\text { İnovasyon AlgıSı -> Teknoloji Yönetimi AR-GE -> Ürün Kalitesi ve } \\
\text { İnovasyonu }\end{array}$ & & $0,057(p: 0,105)$ & Tam Aracılık \\
\hline
\end{tabular}

Tablo 1 incelendiğinde, aracı değişken olmadığı durumdaki sonuçlar ilk sütunda, aracı değişken modelde olduğu durumdaki sonuçlar ise ikinci sütunda gösterilmiştir. Parantez dışındaki değerler standardize doğrudan etkileri, parantez içindeki değerler de bu doğrudan etkilerin anlamlılığını göstermektedir.

İlk aşamada aracı değişkenin modelde olmadığı yani direk etkinin anlamlılığı incelenmiştir. İnovasyon algısından ürün kalitesi ve inovasyonuna giden etkinin istatistiksel olarak anlamlı olduğunu söyleyebiliriz $(p<0,001)$. İkinci aşamada ise aracı değişkenlerin modelde olduğu durumlar incelenmiştir.

“İnovasyon Algısı -> Kıyaslama, Müşteri Odaklılık, Stratejik Plan -> Ürün Kalitesi ve İnovasyonu” aracılık ilişkisinde aracı değişken yokken anlamlı olarak bulunan "İnovasyon Algısı -> Ürün Kalitesi ve İnovasyonu” direk etkisi, aracı değişken modele eklendiğinde de anlamlılı̆ını korumaktadır. Dolayısı ile ilişki hem kıyaslama, müşteri odaklılık, stratejik plan üzerinden hem de direk olarak aktarılmaktadır. Bu durumda kısmi aracılık gerçekleşmiştir. Aracı değişken olmadığı durumda inovasyon algısının ürün kalitesi ve inovasyonu üzerindeki etkisi 0,415 iken kıyaslama aracı değişkeninin modelde olduğu durumda inovasyon algısının ürün kalitesi ve inovasyonu üzerindeki etkisi azalmış ve 0,167'ye düşmüş, müşteri odaklılık aracı değişkeninin modelde olduğu durumda inovasyon algısının ürün kalitesi ve inovasyonu üzerindeki etkisi azalmış ve 0,151 'e düşmüş, stratejik plan aracı değişkeninin modelde olduğu durumda inovasyon algısının ürün kalitesi ve inovasyonu üzerindeki etkisi azalmış ve 0,172'ye düşmüştür.

“inovasyon Algısı -> Teknoloji Yönetimi AR-GE -> Ürün Kalitesi ve İnovasyonu” aracılık ilişkisinde aracı değişken yokken anlamlı olarak bulunan "Inovasyon AlgıSı -> Ürün Kalitesi ve İnovasyonu" direk etkisi, aracı değişken modele eklendiğinde anlamsız olmakta dolayısı ile teknoloji yönetimi AR-GE değişkeni bu ilişkiye tam aracılık etmektedir. Aracı değişken olmadığı durumda inovasyon algısının ürün kalitesi ve inovasyonu üzerindeki etkisi 0,415 iken teknoloji yönetimi AR-GE aracı değişkeninin modelde olduğu durumda inovasyon algısının ürün kalitesi ve inovasyonu üzerindeki etkisi anlamsız hale gelmiştir.

\section{SONUÇ}

Günümüz işletmelerinde inovasyon çalışmalarının en önemli faktörü olarak, inovasyonun sadece işletme yöneticilerinin özgün karar alma yetenekleriyle açıklanamayacağı ve örgütsel bir bütünlük dahilin de çevresiyle yapılan etkileşimli çalışmalar olduğudur. İnovasyon herhangi bir işletmenin çevresiyle olan karşılıklı etkileşimlerini kapsayan faydalar dünyasıdır. İşletmenin kendi içinde sahip olduğu özellikler ile bulunduğu alandaki faaliyetleri işletmelerin davranışını şekillendirmekte çok büyük etkilere sebeptir.

İnovasyon, artık bireysel alandan uluslararası alana kadar her yerde karşımıza çıkmaktadır. İnovasyon bir bütün olarak ele alınması gereken herkesin bir şeyler kattığı katabileceği veya faydalanabildiği evrensel bir kavramdır. Yapılan herhangi bir inovatif hamle hem öncesini hem sonrasını etkileyebilmektedir. Bu da inovasyonun devamlılık arz eden birçok faktörle etkileşim içinde olduğunu gösterir. Çünkü ihtiyaçlar karşılandıkça yeni ihtiyaçlar doğar düşüncesinden hareketle yaşayan, beklenilen ve güncelliği yitirilmeyen bir anlam ifade eder.

İ̧letmelerin ana amacı kar elde etmek ve buna ulaşabilmek için faaliyet gösterdikleri sektörlerde yer alan diğer rakip işletmelerle rekabet etmek zorundadırlar. Değişken olan müşterilerin istek ve beklentilerini karşılamak oldukça zordur. Özellikle müşterilerin kaliteli ve inovatif ürün tercih etmelerinde her geçen gün daha fazla faktör etki etmektedir. Bu faktörlerden en önemlisi de herkesten farklı özeliklere sahip olarak kaliteyi yakalamış müşterinin dikkatini çeken ürünleri ortaya koyabilmektir. Bu bakımdan değerlendirildiğinde pazarda yer alan rakip diğer ürünlerden ayrılabilen inovatif ürünlerin tercih edilmesi giderek artmaktadır.

\section{Teşekkür}

Bu çalışma Muğla Sıtkı Koçman Üniversitesi Bilimsel Araştırma Projeleri Birimi tarafından finanse edilen 'Pazar Rekabeti Kapsamında Yöneticilerin İnovasyon Algısı İle Seçilen Toplam Kalite Uygulamalarının Ürün Kalitesine ve İnovasyonuna Etkisi' adlı 17/262 no'lu Hızı Destek Projesinden üretilmiştir. Muğla Sıtkı Koçman Üniversitesi Bilimsel Araştırma Projeleri Birimi'ne finansal desteği için teşekkürlerimizi borç biliriz. 


\section{KAYNAKLAR}

Choo, C. W. (2002). Information management for the intelligent organization: the art of scanning the environment (3rd Ed.). Medford, NJ: Information Today, Inc.

Deniz, M. (2011). KOBi’lerde yenilik, yenilik stratejileri ve bir uygulama. Selçuk Üniversitesi, iiBF Sosyal ve Ekonomik Araştırmalar Dergisi, Sayı 22, s. 141-175.

Doğan, İ., Ö., Marangoz, M., Topoyan, M., (2003). İşletmelerin iç ve diş pazarda rekabet gücünü etkileyen faktörler ve bir uygulama. Dokuz Eylül Üniversitesi, Sosyal Bilimler Enstitüsü Dergisi, Cilt 5, Sayı:2, s. 118.

Elçi, Ş. (2007). İnovasyon kalkinmanin ve rekabetin anahtarı. İstanbul: Technopolis, s. 2.

Kayabaşı, A., Duran, C., Çetindere, A., (2009). KOBi'lerde yeniliği teşvik eden unsurlar ve yenilik performansi arasindaki ilişkinin incelenmesi. 6. KOBi’ler ve Verimlilik Kongresi Kongre Kitabı, İstanbul Kültür Üniversitesi Yayınları, Yayın No: 129, 17-18 Kasım 2009, İstanbul, s. 449-459.

Schumpeter, J. A. (1934). Theory of economic development. Cambridge: Harvard University Press.

Uzkurt, C., Şen, R., (2012). Örgüt kültürü ve örgütsel yeniliğin pazarlama yeniliğine etkisi: gazli içecek sektöründe bir araştirma. Anadolu Üniversitesi, Sosyal Bilimler Dergisi, Cilt 12, Sayı 3, s. 27-50.

Weerawardena, J. (2003). The role of marketing capability in innovation- based competitive strategy. Journal of Strategic Marketing, Volume 11, Issue 1, p. 15-35. 